Article

\title{
Toxicity of Rhododendron anthopogonoides Essential Oil and Its Constituent Compounds towards Sitophilus zeamais
}

\author{
Kai Yang ${ }^{1}$, Yu Xin Zhou ${ }^{2, *}$, Cheng Fang Wang ${ }^{3}$, Shu Shan Du ${ }^{3}$, Zhi Wei Deng ${ }^{4}$, Qi Zhi Liu ${ }^{1}$ \\ and Zhi Long Liu ${ }^{1, *}$
}

1 Department of Entomology, China Agricultural University, Haidian District, Beijing 100193, China

2 Institute of Chinese Materia Medica, Henan University, Kaifeng 475001, China

3 State Key Laboratory of Earth Surface Processes and Resource Ecology, Beijing Normal University, Beijing 100875, China

4 Analytical and Testing Center, Beijing Normal University, Beijing 100875, China

* Authors to whom correspondence should be addressed; E-Mails: herbcom@163.com (Y.-X.Z.); zhilongliu@cau.edu.cn (Z.-L.L.); Tel.: +86-10-62732800; Fax: +86-10-62208032.

Received: 11 July 2011; in revised form: 15 August 2011 / Accepted: 16 August 2011 /

Published: 25 August 2011

\begin{abstract}
The screening of several Chinese medicinal plants for insecticidal principles showed that essential oil of Rhododendron anthopogonoides flowering aerial parts possessed significant toxicity against maize weevils, Sitophilus zeamais. A total of 37 components were identified in the essential oil and the main constituents of the essential oil were 4-phenyl-2butanone $(27.22 \%)$, nerolidol $(8.08 \%)$, 1,4-cineole $(7.85 \%)$, caryophyllene $(7.63 \%)$ and $\gamma$-elemene $(6.10 \%)$, followed by $\alpha$-farnesene $(4.40 \%)$ and spathulenol $(4.19 \%)$. Repeated bioactivity-directed chromatographic separation on silica gel columns led us to isolate three compounds, namely 4-phenyl-2-butanone, 1,4-cineole, and nerolidol. 4-Phenyl-2-butanone shows pronounced contact toxicity against $S$. zeamais $\left(\mathrm{LD}_{50}=6.98 \mu \mathrm{g} / \mathrm{adult}\right)$ and was more toxic than either 1,4-cineole or nerolidol $\left(\mathrm{LD}_{50}=50.86 \mu \mathrm{g} /\right.$ adult and $29.30 \mu \mathrm{g} / \mathrm{adult}$, respectively) against the maize weevils, while the crude essential oil had a $\mathrm{LD}_{50}$ value of $11.67 \mu \mathrm{g} / \mathrm{adult}$. 4-Phenyl-2-butanone and 1,4-cineole also possessed strong fumigant toxicity against the adults of $S$. zeamais $\left(\mathrm{LC}_{50}=3.80 \mathrm{mg} / \mathrm{L}\right.$ and $\left.21.43 \mathrm{mg} / \mathrm{L}\right)$ while the crude essential oil had a $\mathrm{LC}_{50}$ value of $9.66 \mathrm{mg} / \mathrm{L}$.
\end{abstract}

Keywords: Rhododendron anthopogonoides; Sitophilus zeamais; contact toxicity; fumigant; 4-phenyl-2-butanone; essential oil composition 


\section{Introduction}

Currently, control of stored product insects relies heavily on the use of synthetic insecticides and fumigants, which has led to problems such as disturbance of the environment, increasing application costs, pest resurgence, pest resistance to pesticides and lethal effects on non-target organisms in addition to direct toxicity to the users [1]. Thus, there is a considerable interest in developing natural products that are relatively less damaging to mammalian health and the environment than existing conventional pesticides, as alternatives to non-selective synthetic pesticides to control the pests of medical and economic importance [2,3]. In recent years, various workers have been concentrating their efforts on the search for natural products as an alternative to conventional insecticides and fumigants, as well as the re-evaluation of traditional botanical pest control agents [4-11].

Botanical pesticides have the advantage of providing novel modes of action against insects that can reduce the risk of cross-resistance, as well as offering new leads for the design of target-specific molecules [2]. During a screening program for new agrochemicals from Chinese medicinal herbs and local wild plants, the essential oil derived from flowering aerial parts of Rhododendron anthopogonoides Maxim. (Family: Ericaceae) was found to possess strong insecticidal activity against the maize weevil, Sitophilus zeamais Motsch. $R$. anthopogonoides is a shrub, growing on the damp sides of mountains and widely distributed in northwest China, especially in Sichuan, Qinghai, and Gansu provinces [12]. Its flowers, leaves, and twigs are used as traditional Chinese folk medicine for treating chronic bronchitis and coronary heart disease [13]. Investigations have shown that the crude drug contains monterpenoids, sesquiterpenoids, triterpenoids, flavonoids, steroids, coumarins, lignans, cerebrosides, tetracyclic chromane derivatives, tannins, and alkaloids [14-21]. The essential oil of this medicinal herb has also been investigated in the previous studies [22-26]. The essential oil of $R$. anthopogonoides aerial parts was demonstrated to inhibit growth of bacteria (Bacillus subtilis, Escherichia coli, Proteus vulgaris, and Staphyloccocus aureus) [23]. Moreover, the essential oil of $R$. anthopogonoides exhibited strong antifeedant, stomach poison, contact toxicity, and growth inhibitory effects to the larvae of grassland caterpillar (Gynaephora menyuanenis) [27]. However, no compounds active against stored product insects were isolated from the essential oil of $R$. anthopogonoides so far. In this paper, we report the isolation of three components derived from this essential oil active against the maize weevil and the chemical composition and insecticidal activities of the essential oil of $R$. anthopogonoides were also determined.

\section{Results and Discussion}

\subsection{Isolated Bioactive Compounds}

Three bioactive compounds were isolated and based on bioassay-guided fractionation and identified based on their spectroscopic data and comparison with literature values. Their chemical structures are given in Figure 1. 
Figure 1. Structures of active compounds isolated from $R$. anthopogonoides flowering aerial parts.

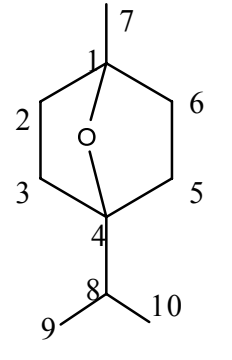

1,4-Cineole (1)

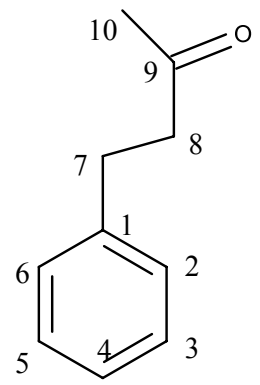

4-Phenyl-2-butanone (2)

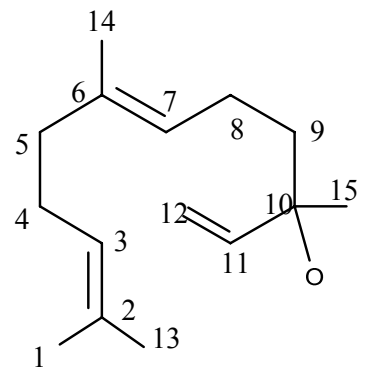

Nerolidol (3)

Among the five major components of $R$. anthopogonoides essential oil, only three of them have been isolated. Caryophyllene and $\gamma$-elemene were not isolated in the present study by using bioactivityguided fractionation. It maybe the concentrations used to test fractionation was too low.

\subsection{Chemical Constituents of the Essential Oil}

The oil yield of $R$. anthopogonoides flowering aerial parts was $0.86 \% \mathrm{v} / \mathrm{w}$ and the density of the concentrated extract was determined to be $0.92 \mathrm{~g} / \mathrm{mL}$. The GC-MS results for $R$. anthopogonoides essential oil are presented in Table 1. A total of 37 components were identified in the essential oil, accounting for $95.03 \%$ of the total oil (Table 1) and the main constituents of the essential oil were 4-phenyl-2-butanone (27.22\%), nerolidol (8.08\%), 1,4-cineole (7.85\%), caryophyllene (7.63\%) and $\gamma$-elemene $(6.10 \%)$, followed by $\alpha$-farnesene $(4.40 \%)$ and spathulenol $(4.19 \%)$. The chemical composition of the essential oil was different from that reported in other studies. For example, 4-phenyl-2-butanone (50\%) was the main constituent of $R$. anthopogonoides (leaves and young twigs, collected from Datong, Qinghai Province, 36.92 $\mathrm{N}$ latitude and $101.67^{\circ} \mathrm{E}$ longitude) essential oil, followed by selina-3,7(11)-diene (20\%) and neofuranodiene (10\%) [24], while Li et al. [25] found that the essential oil of $R$. anthopogonoides (also harvested from Datong, Qinghai Province) contained 4-phenyl-2-butanone (52.16\%), D-limonene (4.81\%), eudesma-3,7(13)-diene (4.34\%), and $\beta$-myrcene (4.19\%). However, methyl palmitate (17.08\%), dibutyl phthalate $(15.77 \%)$ and $\gamma$-cadinene $(5.33 \%)$ were the main constituents of $R$. anthopogonoides young aerial parts, harvested from Guide, Qinghai Province (36.04 ${ }^{\circ} \mathrm{N}$ latitude and $101.43^{\circ} \mathrm{E}$ longitude) essential oil [23]. The essential oil of R. anthopogonoides (aerial parts, collected from Tianzhu, Gansu Province, $37.24^{\circ} \mathrm{N}$ latitude and $102.84^{\circ}$ E longitude) contained 3,7-cyclodecane-1-one (15.53\%), 4-phenyl-2-butanone (13.11\%), 1-propoxy-1,3-dimethoxylbene $\quad(10.80 \%), \quad O$ - $(O$-methoxyphenoxy) phenol $(6.65 \%)$ and $4 \alpha$-methyldecahydro-naphthalene (5.94\%). The above results show the wide variation in chemical composition and yield of $R$. anthopogonoides essential oil, which may be related to the herbal source (climate, soil conditions and geographical location), herbal parts used, collection time (seasonal factors), chemotype of the plant species, and/or the analytical methods used. However, 4-phenyl-2butanone was demonstrated to be one of major constituents of the essential oil in all the previous reports, as well as in the present experiments. Moreover, the above findings suggest that further studies on plant cultivation and essential oil standardization are needed because the chemical composition of the essential oil of $R$. anthopogonoides varies greatly with the plant population. 
Table 1. Chemical composition of the essential oil of $R$. anthopogonoides flowering aerial parts.

\begin{tabular}{|c|c|c|}
\hline Compounds & RI * & Relative content $(\%)$ \\
\hline$\beta$-Thujene & 920 & 2.38 \\
\hline$\alpha$-Pinene & 939 & 0.78 \\
\hline Camphene & 954 & 0.69 \\
\hline$\beta$-Pinene & 974 & 0.22 \\
\hline$\beta$-Myrcene & 991 & 0.54 \\
\hline 1,4-Cineole & 1018 & 7.85 \\
\hline$(+)$-Limonene & 1029 & 1.17 \\
\hline 1,8-Cineole & 1031 & 0.98 \\
\hline (E)- $\beta$-Ocimene & 1068 & 0.24 \\
\hline Linalool & 1097 & 0.31 \\
\hline 4-Terpineol & 1177 & 1.48 \\
\hline$\alpha$-Terpineol & 1188 & 0.97 \\
\hline 4-Phenyl-2-butanone & 1218 & 27.22 \\
\hline$\gamma$-Pyronene & 1338 & 0.12 \\
\hline Longipinene & 1350 & 0.14 \\
\hline$\alpha$-Ylangene & 1370 & 1.41 \\
\hline$\alpha$-Copaene & 1375 & 1.59 \\
\hline$\beta$-Elemene & 1389 & 0.27 \\
\hline (Z)-Caryophyllene & 1409 & 1.79 \\
\hline$\alpha$-Gurjunene & 1411 & 0.81 \\
\hline$\alpha$-Santalene & 1420 & 0.57 \\
\hline Caryophyllene & 1423 & 7.63 \\
\hline$\alpha$-Bergamotene & 1433 & 0.97 \\
\hline$\gamma$-Elemene & 1437 & 6.10 \\
\hline 2,3-Dimethylnaphthalene & 1443 & 0.29 \\
\hline$\beta$-Farnesene & 1453 & 0.23 \\
\hline $\begin{array}{l}\text { 1,4,7,-Cycloundecatriene, } \\
\text { 1,5,9,9-tetramethyl-, Z,Z,Z- }\end{array}$ & 1456 & 1.82 \\
\hline Curcumene & 1481 & 0.63 \\
\hline$\alpha$-Farnesene & 1505 & 4.40 \\
\hline$\beta$-Sesquiphellandrene & 1523 & 3.09 \\
\hline Nerolidol & 1567 & 8.08 \\
\hline Dendrolasin & 1571 & 1.13 \\
\hline Spathulenol & 1578 & 4.19 \\
\hline$(+)$-Viridiflorol & 1588 & 0.55 \\
\hline trans- $\beta$-Elemenone & 1597 & 1.83 \\
\hline$\alpha$-Santalol & 1681 & 2.32 \\
\hline Total & & 95.03 \\
\hline
\end{tabular}

* RI, retention index as determined on a HP-5MS column using the homologous series of $n$-hydrocarbons as reference. 


\subsection{Contact and Fumigant Toxicity}

4-Phenyl-2-butanone shows pronounced contact toxicity against $S$. zeamais $\left(\mathrm{LD}_{50}=6.98 \mu \mathrm{g} / \mathrm{adult}\right)$ while the crude essential oil had a $\mathrm{LD}_{50}$ value of $11.67 \mu \mathrm{g} /$ adult (Table 2). 1,4-Cineole and nerolidol also exhibited contact toxicity against $S$. zeamais $\left(\mathrm{LD}_{50}=50.86 \mu \mathrm{g} / \mathrm{adult}\right.$, and $29.30 \mu \mathrm{g} / \mathrm{adult}$, respectively). Only 4-phenyl-2-butanone exhibits stronger contact toxicity than the crude essential oil against the maize weevils. 1,4-Cineole and nerolidol exhibit 4- and 2-times less activity against S. zeamais, respectively. The above results indicated that constituent compounds may have synergistic action or compound(s) with stronger toxicity in the essential oil were not isolated. However, when compared with the famous botanical insecticide, pyrethrum extract (25\% pyrethrine I and pyrethrine II), 4-phenyl-2-butanone exhibits the same level of contact toxicity against the maize weevils and the essential oils were almost 2 times less active against $S$. zeamais adults because pyrethrum extract displayed a $\mathrm{LD}_{50}$ value of $4.87 \mu \mathrm{g} /$ adult (Table 2). Compared with pyrethrum extract, 1,4-cineole and nerolidol were 10 - and 6-times less active against $S$. zeamais, respectively.

Table 2. Toxicity of compounds isolated from $R$. anthopogonoides flowering aerial parts against $S$. zeamais adults.

\begin{tabular}{|c|c|c|c|c|c|c|}
\hline \multirow[b]{2}{*}{ Compounds } & \multicolumn{3}{|c|}{ Contact Toxicity } & \multicolumn{3}{|c|}{ Fumigant Toxicity } \\
\hline & $\begin{array}{l}7 \text { d LD }_{50} \\
\text { ( } \mu \text { g/adult) } \\
\text { (95\% FL) } \\
\end{array}$ & Slope \pm SE & $\begin{array}{c}\text { Chi } \\
\text { square } \\
\left(\chi^{2}\right) \\
\end{array}$ & $\begin{array}{c}7 \text { d LC }_{50} \\
(\mathrm{mg} / \mathrm{L}) \\
(95 \% \text { FL) } \\
\end{array}$ & Slope \pm SE & $\begin{array}{c}\text { Chi } \\
\text { Square } \\
\left(\chi^{2}\right) \\
\end{array}$ \\
\hline $\begin{array}{l}\text { 4-Phenyl-2- } \\
\text { butanone }\end{array}$ & $\begin{array}{c}6.98 \\
(6.63-7.36)\end{array}$ & $8.22 \pm 0.92$ & 13.12 & $\begin{array}{c}3.80 \\
(3.48-4.20)\end{array}$ & $6.67 \pm 0.49$ & 14.95 \\
\hline 1,4-Cineole & $\begin{array}{c}50.86 \\
(46.14-56.62)\end{array}$ & $4.01 \pm 0.41$ & 19.32 & $\begin{array}{c}21.43 \\
(20.64-25.04)\end{array}$ & $4.14 \pm 0.47$ & 16.52 \\
\hline Nerolidol & $\begin{array}{c}29.30 \\
(26.54-31.86)\end{array}$ & $4.52 \pm 0.49$ & 22.68 & $>353.00$ & - & - \\
\hline Crude oil & $\begin{array}{c}11.67 \\
(10.98-12.84)\end{array}$ & $5.99 \pm 0.61$ & 11.96 & $\begin{array}{c}9.66 \\
(8.79-10.64)\end{array}$ & $4.43 \pm 0.50$ & 13.80 \\
\hline $\begin{array}{l}\text { Pyrethrum } \\
\text { extract }\end{array}$ & $\begin{array}{c}4.87 \\
(4.36-5.32)\end{array}$ & $0.73 \pm 0.021$ & 13.51 & - & - & - \\
\hline $\mathrm{MeBr} *$ & - & & & 0.67 & - & - \\
\hline
\end{tabular}

* data from Liu and Ho [28].

4-Phenyl-2-butanone and 1,4-cineole also possess fumigant toxicity against $S$. zeamais $\left(\mathrm{LC}_{50}=3.80 \mathrm{mg} / \mathrm{L}\right.$, and $21.43 \mathrm{mg} / \mathrm{L}$, respectively), while the crude essential oil showed a $\mathrm{LC}_{50}$ value of $9.66 \mathrm{mg} / \mathrm{L}$ (Table 2) and nerolidol did not exhibit any fumigant toxicity against $S$. zeamais at the concentrations tested. 4-Phenyl-2-butanone was a bioactive (fumigant) constituent in the essential oil because it was 2.5 times more toxic to the maize weevils than the crude essential oil. The commercial grain fumigant, methyl bromide $(\mathrm{MeBr})$ was reported to have fumigant activity against $S$. zeamais adults with a $\mathrm{LC}_{50}$ value of $0.67 \mathrm{mg} / \mathrm{L}$ [28], thus the isolated constituent 4-phenyl-2-butanone and the essential oil were 6- or 14-times less toxic to $S$. zeamais adults compared with $\mathrm{MeBr}$. However, compared with other essential oils reported in the literature, the essential oil of $R$. anthopogonoides flowering aerial parts exhibited stronger than or the same level of fumigant toxicity against the maize weevils, e.g., essential 
oils of Murraya exotica $\left(\mathrm{LC}_{50}=8.29 \mathrm{mg} / \mathrm{L}\right)$ [31], Artemisia lavandulaefolia $\left(\mathrm{LC}_{50}=11.2 \mathrm{mg} / \mathrm{L}\right)$ [30], A. vestita $\left(\mathrm{LC}_{50}=13.42 \mathrm{mg} / \mathrm{L}\right)$ [32], Illicium simonsii $\left(\mathrm{LC}_{50}=14.95 \mathrm{mg} / \mathrm{L}\right)$ [32], A. sieversiana $\left(\mathrm{LC}_{50}=15.0 \mathrm{mg} / \mathrm{L}\right)[30]$, and Ostericum sieboldii $(20.92 \mathrm{mg} / \mathrm{L})[34]$.

Considering the currently used fumigants are synthetic insecticides, the fumigant activity of the crude essential oil and the two isolated compounds are quite promising and they show potential for development as possible natural fumigants for the control of stored product insects. For the practical use of $R$. anthopogonoides essential oil and their constituents as novel fumigants or insecticides to proceed, further research is needed to establish their human safety and to evaluate the toxicity against other species. Additionally, their fumigant and insecticide modes of action need to be established and formulations for improving insecticidal potency and stability, thereby reducing costs, need to be developed.

\section{Experimental}

\subsection{General}

${ }^{1} \mathrm{H}-\mathrm{NMR}$ spectra were recorded on Bruker (Fallanden, Switzerland) ACF300 [300 MHz $\left.\left({ }^{1} \mathrm{H}\right)\right]$ and AMX500 [500 MHz $\left.\left({ }^{1} \mathrm{H}\right)\right]$ instruments using deuterochloroform $\left(\mathrm{CDCl}_{3}\right)$ as the solvent with tetramethylsilane (TMS) as the internal standard. Electron impact mass spectra (EIMS) were determined on a ThermoQuest Trace 2000 mass spectrometer at $70 \mathrm{eV}$ (probe). Silica gel (160-200 mesh) and pre-coated $\mathrm{GF}_{254}$ plates were purchased from Qingdao Marine Chemical Plant (Shandong Province, China). Fluon was purchased from ICI America Inc (Bridgewater, NJ, USA). $\mathrm{C}_{8}-\mathrm{C}_{24} n$-alkanes were purchased from Sigma-Aldrich (USA). All other chemicals and reagents were of analytical grade.

\subsection{Plant Material}

Fresh flowering aerial parts (10 $\mathrm{kg}$ of leaves, stems and flowers) of $R$. anthopogonoides were harvested in July 2009 from Guide (36.04 ${ }^{\circ} \mathrm{N}$ latitude and $101.43^{\circ} \mathrm{E}$ longitude), Qinghai Province, China. The aerial parts were air-dried for one week and ground to a powder. The plant species was identified and the voucher specimens (CAU-liuzhilong-2009-07-09-011) were deposited at the Department of Entomology, China Agricultural University. The ground powder of R. anthopogonoides was subjected to hydrodistillation using a modified Clevenger-type apparatus for $6 \mathrm{~h}$ and extracted with $n$-hexane. Anhydrous sodium sulphate was used to remove water after extraction. Essential oil was stored in an airtight container in a refrigerator at $4{ }^{\circ} \mathrm{C}$.

\subsection{Insects}

The maize weevils ( $S$. zeamais) were obtained from laboratory cultures maintained in the dark in incubators at $28-30{ }^{\circ} \mathrm{C}$ and $70 \%-80 \%$ relative humidity. The insects were reared on whole wheat at $12 \%-13 \%$ moisture content. Unsexed adult weevils used in all the experiments were about 2 weeks old.

\subsection{Gas Chromatography and Mass Spectrometry}

Gas chromatographic analysis was performed on an Agilent 6890N instrument (Agilent Technologies, Santa Clara, CA, USA) equipped with a flame ionization detector and an HP-5MS 
$(30 \mathrm{~m} \times 0.25 \mathrm{~mm} \times 0.25 \mu \mathrm{m})$ capillary column, while the essential oil components were identified on an Agilent Technologies 5973N mass spectrometer. The GC settings were as follows: The initial oven temperature was held at $60{ }^{\circ} \mathrm{C}$ for $1 \mathrm{~min}$ and ramped at $10{ }^{\circ} \mathrm{C} \min ^{-1}$ to $180{ }^{\circ} \mathrm{C}$ for $1 \mathrm{~min}$, and then ramped at $20{ }^{\circ} \mathrm{C} \min ^{-1}$ to $280{ }^{\circ} \mathrm{C}$ for $15 \mathrm{~min}$. The injector temperature was maintained at $270{ }^{\circ} \mathrm{C}$. The samples $(1 \mu \mathrm{L})$ were injected neat, with a split ratio of 1:10. The carrier gas was helium at flow rate of $1.0 \mathrm{~mL} \mathrm{~min}^{-1}$. Spectra were scanned from 20 to $550 \mathrm{~m} / \mathrm{z}$ at $2 \mathrm{scans} \mathrm{s}^{-1}$. Most constituents were identified by gas chromatography by comparison of their retention indices with those of the literature [22-26] or with those of authentic compounds available in our laboratories. The retention indices were determined in relation to a homologous series of $n$-alkanes $\left(\mathrm{C}_{8}-\mathrm{C}_{24}\right)$ under the same operating conditions. Further identification was made by comparison of their mass spectra with those stored in NIST 05 and Wiley 275 libraries or with mass spectra from the literature [35]. Component relative percentages were calculated based on GC peak areas without using correction factors.

\subsection{Contact Toxicity Using Topical Application}

The contact toxicity of the essential oil and isolated compounds against $S$. zeamais adults was measured as described by Liu and Ho [28]. Range-finding studies were run to determine the appropriate testing concentrations. A serial dilution of the essential oil/compounds $(15.0 \%-1.0 \%$ for S. zeamias, $\mathrm{v} / \mathrm{w}$, five concentrations) was prepared in $n$-hexane. Initial experiments were conducted to determine appropriate ranges of testing concentrations. Aliquots $(0.5 \mu \mathrm{L})$ of the dilutions were applied topically to the dorsal thorax of the insects. Controls were determined using $n$-hexane. Both treated and control insects were then transferred to glass vials (10 insects/vial) with culture media and kept in incubators at $29-30{ }^{\circ} \mathrm{C}, 70 \%-80 \%$ r.h. Mortality of insects was observed daily until end-point mortality was reached one week after treatment. The experiments were repeated in three times. The $\mathrm{LD}_{50}$ values were calculated by using Probit analysis [29]. The positive control, pyrethrum extract (25\% pyrethrine I and pyrethrine II), was purchased from Fluka Chemie.

\subsection{Fumigant Toxicity}

The fumigant activity of the essential oil and the pure compounds against $S$. zeamais adults was tested as described by Liu and Ho [28]. A serial dilution of the essential oil and isolated compounds was prepared in $n$-hexane. Filter papers (Whatman Cat No. 1001020, diameter $2.0 \mathrm{~cm}$ ) were each impregnated with $20 \mu \mathrm{L}$ of an appropriate concentration $(25.0 \%-1.0 \%$ for $S$. zeamias, v/w, five concentrations) of the essential oil/compounds, and placed on the underside of the screw cap of a glass vial (diameter $2.5 \mathrm{~cm}$, height $5.5 \mathrm{~cm}, 25 \mathrm{~mL}$ ). Preliminary range finding studies were performed with each of the compounds/essential oil to determine the appropriate testing concentrations. Fluon was used inside glass vial to prevent insects from the treated filter paper. The solvent was allowed to evaporate for $30 \mathrm{~s}$ before the cap was screwed tightly on the glass vial containing 10 insects. Preliminary experiments demonstrated that $30 \mathrm{~s}$ was sufficient for the evaporation of solvents. $n$-Hexane was used as a control. Five replicates were carried out for all treatments and controls, and they were incubated for $24 \mathrm{~h}$. The insects were then transferred to clean vials with some culture media and returned to the incubator and observed daily for determination of end-point mortality, which was 
reached after one week. The experiments were repeated in three times. The $\mathrm{LC}_{50}$ values were calculated using Probit analysis [29].

\subsection{Isolation of Active Ingredients}

The crude essential oil ( $25 \mathrm{~mL}$ ) was chromatographed on a silica gel (Merck 9,385, 1,000g, Merck Chemicals Co., Ltd., Shanghai, China) column ( $85 \mathrm{~mm}$ i.d., $850 \mathrm{~mm}$ length) by gradient elution with a mixture of solvents ( $n$-hexane, $n$-hexane-ethyl acetate, and acetone). Fractions of $500 \mathrm{~mL}$ were collected and concentrated at $40{ }^{\circ} \mathrm{C}$, and similar fractions according to TLC profiles were combined to yield 28 fractions. Fractions (7, 11 and 19) that possessed contact/fumigant toxicity, with similar TLC profiles, were pooled and further purified by preparative silica gel column chromatography (PTLC) until to obtain three pure compounds for determining structure as 1,4-cineole (1, $1.2 \mathrm{~g})$, 4-phenyl-2butanone $(2,1.7 \mathrm{~g})$ and nerolidol $(3,1.9 \mathrm{~g})$. The structures of the compounds were elucidated based on high-resolution electron impact mass spectrometry and nuclear magnetic resonance.

\subsection{Compound Characterization}

1,4-Cineole (1), colorless oil. EI-MS m/z (\%): 154 (26), 125 (29), 111 (73), 71 (60), 69 (35), 55 (41), 43 (100), 41 (44), 27 (22). $\mathrm{C}_{10} \mathrm{H}_{18} \mathrm{O} .{ }^{1} \mathrm{H}-\mathrm{NMR}\left(500 \mathrm{MHz}, \mathrm{CDCl}_{3}\right) \delta$ (ppm): 0.93 (3H, s, 9- $\left.\mathrm{CH}_{3}\right), 0.94$ $\left(3 \mathrm{H}, \mathrm{s}, 10-\mathrm{CH}_{3}\right), 1.42\left(3 \mathrm{H}, \mathrm{s}, 7-\mathrm{CH}_{3}\right), 1.48-1.67\left(8 \mathrm{H}, \mathrm{m}, 2-\mathrm{CH}_{2}, 3-\mathrm{CH}_{2}, 5-\mathrm{CH}_{2}, 6-\mathrm{CH}_{2}\right), 2.04(1 \mathrm{H}, \mathrm{m}$, $J=13.7,6.8 \mathrm{~Hz}, \mathrm{H}-8) .{ }^{13} \mathrm{C}-\mathrm{NMR}\left(125 \mathrm{MHz}, \mathrm{CDCl}_{3}\right) \delta(\mathrm{ppm}): 18.12$ (C-9), 18.18 (C-10), 21.22 (C-7), 32.92 (C-3, C-5), 33.06 (C-2, C-6), 37.22 (C-8), 82.96 (C-1), 89.68 (C-4). The data matched with the previous reports $[36,37]$.

4-Phenyl-2-butanone (2), colorless oil, EI-MS m/z (\%): 149 (8), 148 (73), 133 (14), 105 (81), 104 (11), 91 (60), 79 (13), 78 (11), 77 (17), 43 (100), 51 (11). $\mathrm{C}_{10} \mathrm{H}_{12} \mathrm{O} .{ }^{1} \mathrm{H}-\mathrm{NMR}$ (500 MHz, CDCl ${ }_{3}$ ) $\delta$ (ppm): $2.11\left(3 \mathrm{H}, \mathrm{s}, 9-\mathrm{CH}_{3}\right), 2.73\left(2 \mathrm{H}, \mathrm{t}, J=8.0 \mathrm{~Hz}, 7-\mathrm{CH}_{2}\right), 2.90\left(2 \mathrm{H}, \mathrm{t}, J=8.0 \mathrm{~Hz}, 8-\mathrm{CH}_{2}\right), 7.19(1 \mathrm{H}$, dd, $J=8.0 \mathrm{~Hz}, 4-\mathrm{H}), 7.21(2 \mathrm{H}, \mathrm{d}, J=12.0,8.0 \mathrm{~Hz}, \mathrm{H}-2, \mathrm{H}-6), 7.30$ (2H, dd, $J=12.0,8.0 \mathrm{~Hz}, \mathrm{H}-3, \mathrm{H}-5)$. ${ }^{13} \mathrm{C}-\mathrm{NMR}\left(125 \mathrm{MHz}, \mathrm{CDCl}_{3}\right) \delta(\mathrm{ppm}): 29.74$ (C-10), 29.95 (C-7), 45.02 (C-8), $126.12(\mathrm{C}-4), 128.35$ (C-3, C-5), 128.51 (C-2, C-6), 141.10 (C-1), 207.62 (C-9). The ${ }^{1} \mathrm{H}$ and ${ }^{13} \mathrm{C}-\mathrm{NMR}$ data were in agreement with the reported data $[38,39]$.

Nerolidol (3), colorless oil. EI-MS m/z (\%): 204 (3), 161 (11), 136 (15), 107 (24), 93 (50), 81 (27), 71 (37), 69 (100), 55 (26), 43 (28), 41 (65). $\mathrm{C}_{15} \mathrm{H}_{26} \mathrm{O} .{ }^{1} \mathrm{H}-\mathrm{NMR}\left(500 \mathrm{MHz}, \mathrm{CDCl}_{3}\right) \delta$ (ppm): $1.29(3 \mathrm{H}$, s, $\left.15-\mathrm{CH}_{3}\right), 1.56\left(2 \mathrm{H}, \mathrm{m}, J=9.8,6.1 \mathrm{~Hz}, 9-\mathrm{CH}_{2}\right), 1.59\left(3 \mathrm{H}, \mathrm{s}, 1-\mathrm{CH}_{3}\right), 1.60\left(3 \mathrm{H}, \mathrm{s}, 13-\mathrm{CH}_{3}\right), 1.69(3 \mathrm{H}$, s, 14- $\left.\mathrm{CH}_{3}\right), 1.76(1 \mathrm{H}, \mathrm{br}, 10-\mathrm{OH}), 1.97-2.09\left(6 \mathrm{H}, 4-\mathrm{CH}_{2}, 5-\mathrm{CH}_{2}, 8-\mathrm{CH}_{2}\right), 5.04-5.12\left(2 \mathrm{H}, \mathrm{m}, 12-\mathrm{CH}_{2}\right)$, $5.15(1 \mathrm{H}, \mathrm{t}, 3-\mathrm{H}), 5.22(1 \mathrm{H}, \mathrm{dd}, J=17.3,1.2 \mathrm{~Hz}, 7-\mathrm{H}), 5.92(1 \mathrm{H}, \mathrm{m}, J=17.3,10.7 \mathrm{~Hz}, 11-\mathrm{H})$. ${ }^{13} \mathrm{C}-\mathrm{NMR}\left(125 \mathrm{MHz}, \mathrm{CDCl}_{3}\right.$ ) $\delta(\mathrm{ppm}): 16.01$ (C-14), 17.69 (C-8), 22.72 (C-1), $25.71(\mathrm{C}-4), 26.63$ (C-13), 27.86 (C-15), 39.70 (C-5), 42.04 (C-9), 73.49 (C-10), 111.67 (C-12), 124.22 (C-3), 124.24 (C-7), 131.41 (C-2), 135.52 (C-6), 145.05 (C-11). The data matched with the previous reports [40]. 


\section{Conclusions}

Based on mass screening of medicinal herbs, the essential oil of $R$. anthopogonoides flowering aerial parts was found to possess toxicity against the maize weevils ( $S$. zeamais). Three active constituents were isolated from the oil by bioactivity-guided fractionation and identified. 4-Phenyl-2butanone exhibits the same level of contact toxicity against the maize weevils and the essential oils were 2-times less active against $S$. zeamais adults when compared with pyrethrum extract. Moreover, the isolated constituent 4-phenyl-2-butanone and the essential oil exhibit strong fumigant toxicity against $S$. zeamais adults, although they were 6- or 14-times less toxic when compared with $\mathrm{MeBr}$. These findings suggest that essential oil of $R$. anthopogonoides and the three compounds may have potential to be developed as new natural fumigants/insecticides for the control stored product insects.

\section{Acknowledgements}

This work was funded by the Hi-Tech Research and Development of China 2011AA10A202 and 2006AA10A209 and National New-drug Innovation Project 2009ZX09501-014. We thank Liu Q.R. from the College of Life Sciences, Beijing Normal University, Beijing 100875, for the identification of the investigated medicinal herb.

\section{References and Notes}

1. Zettler, J.L.; Arthur, F.H. Chemical control of stored product insects with fumigants and residual treatments. Crop Prot. 2000, 19, 577-582.

2. Isman, M.B. Botanical insecticides, deterrents, and repellents in modern agriculture and an increasingly regulated world. Ann. Rev. Entomol. 2006, 51, 45-66.

3. Rajendran, S.; Srianjini, V. Plant products as fumigants for stored-product insects control. J. Stored Prod. Res. 2008, 44, 126-135.

4. Wu, H.; Zhang, G.A.; Zeng, S.Y.; Lin, K.C. Extraction of allyl isothiocyanate from horseradish (Armoracia rusticana) and its fumigant insecticidal activity on four stored-product pests of paddy. Pest Manag. Sci. 2009, 65, 1003-1008.

5. Wang, J.L.; Li, Y.; Lei, C.L. Evaluation of monoterpenes for the control of Tribolium castaneum (Herbst) and Sitophilus zeamais Motsch. Nat. Prod. Res. 2009, 23B, 1080-1088.

6. Liu, Z.L.; Chu, S.S.; Jiang, G.H. Feeding deterrents from Zanthoxylum schinifolium against two stored-product insects. J. Agric. Food Chem. 2009, 57, 10130-10133.

7. Chu, S.S.; Hu, J.F.; Liu, Z.L. Composition of essential oil of Chinese Chenopodium ambrosioides and insecticidal activity against maize weevil, Sitophilus zeamais. Pest Manag. Sci. 2011, 67, 714-718.

8. Liu, Z.L.; Chu, S.S.; Jiang, G.H. Toxicity of Schizonepeta multifida essential oil and its constituent compounds towards two grain storage insects. J. Sci. Food Agric. 2011, 91, 905-909.

9. Chu, S.S.; Jiang, G.H.; Liu, Z.L. Insecticidal components from the essential oil of Chinese medicinal herb, Ligusticum chuanxiong Hort. E-J. Chem. 2011, 8, 300-304. 
10. Mossi, A.J.; Astolfi, V.; Kubiak, G.; Lerin, L.; Zanella, C.; Toniazzo, G.; Oliveira, D.; Treichel, H.; Devilla, I.A.; Cansian, R.; Restello, R. Insecticidal and repellency activity of essential oil of Eucalyptus sp. against Sitophilus zeamais Motschulsky (Coleoptera, Curculionidae). J. Sci. Food Agric. 2011, 91, 273-277.

11. Suthisut, D.; Fields, P.G.; Chandrapatya, A. Fumigant toxicity of essential oils from three Thai plants (Zingiberaceae) and their major compounds against Sitophilus zeamais, Tribolium castaneum and two parasitoids. J. Stored Prod. Res. 2011, 47, 222-230.

12. Committee of Flora of China. Flora of China; Science Press: Beijing, China, 1999; Volume 57, p. 180.

13. Jiangsu New Medical College. Dictionary of Chinese Herbal Medicine; Shanghai Science and Technology Press: Shanghai, China, 1977; pp. 264-265.

14. Iwata, N.; Kitanaka, S. Tetracyclic chromane derivatives from Rhododendron anthopogonoides. J. Nat. Prod. 2010, 73, 1203-1206.

15. Zhao, L.; Ge, J.; Qiao, C.; Zhang, H.; Jiang, S. Separation and quantification of flavonoid compounds in Rhododendron anthopogonoides Maxim by high-performance liquid chromatography. Acta Chromatogr. 2008, 20, 135-146.

16. Zhang, Z.L.; Chuan, F.Y.; Liu, Y.L. Studies on the chemical constituents of Rhododendron anthopogonoides. Chin. Tradit. Herb. Drugs 1980, 11, 393-394 (in Chinese with English abstract).

17. Zheng, S.Z.; Ma, X.M.; Sheng, Q.; Yang, H.P.; Shen, X.W. Chemical constituents of Rhododendron anthopogonoides Maxim. Nat. Prod. Res. Develop. 2003, 15, 387-389.

18. Dai, S.J.; Yu, D.Q. Triterpenoids of Rhododendron anthopogonoides. Chin. J. Nat. Med. 2005, 3, 347-349 (in Chinese with English abstract).

19. Dai, S.J.; Chen, R.Y.; Zhang, P.C.; Yu, D.Q. A new compound from Rhododendron anthopogonoides Maxim. J. Asian Nat. Prod. Res. 2005, 7, 681-685.

20. Dai, S.J.; Chen, R.Y.; Yu, D.Q. Studies on the flavonoid compounds of Rhododendron anthopogonoides. China J. Chin. Materia Med. 2004, 29, 44-47 (in Chinese with English abstract).

21. Dai, S.J.; Yu, D.Q. Studies on flavonoids in stem of Rhododendron anthopogonoides II. China J. Chin. Materia Med. 2005, 30, 1830-1833 (in Chinese with English abstract).

22. Shi, Z.X. Gas-liquid chromatographic analysis of essential oils from four species of Rhododendron on Qinghai plateau. Chin. Tradit. Herb. Drugs 1981, 12, 15-17 (in Chinese with English abstract).

23. Liu, B. Chemical components and antimicrobial effect of volatile oil from Rhododendron anthopogonoides. Pratacultural Sci. 2007, 24, 61-63 (in Chinese with English abstract).

24. Lu, Y.C.; Wang, Y.L.; Bai, Y.F. Study on the chemical composition of the essential oil of Rhododendron anthopogonoides Maxim. Acta Chim. Sin. 1980, 38, 140-148 (in Chinese with English abstract).

25. Li, W.W.; Hu, F.Z.; Shi, Z.X. Study on the chemical compounds in the volatile oils of the Tibetan medicine, Rhododendron anthopogonoides. J. Yunnan Univ. 2004, 26, 48-51 (in Chinese with English abstract).

26. Zhang, J.; Ma, J.Y.; Yang, Y.L.; Yao, J.; Huang, A.L.; Gao, L.M.; Zhao, W.J. GC-MS analysis of volatile constituents from Rhododendron anthopogonoides. Chin. Tradit. Herb. Drugs 2003, 34, 304-305 (in Chinese with English abstract). 
27. Yan, L.; Hu, F.Z.; Wu, J.; Han, F.L. The biological activity of essential oil in Rhododendron anthopogonoides Maxim and Artemisia dubia Wall. ex Bess. to grassland caterpillar, Gynaephora menyuanenis (Lepidoptera: Lymantriidae). Acta Agric. Boreali-Occidentalis Sin. 2009, 18, 58-63 (in Chinese with English abstract).

28. Liu, Z.L.; Ho, S.H. Bioactivity of the essential oil extracted from Evodia rutaecarpa Hook f. et Thomas against the grain storage insects, Sitophilus zeamais Motsch. and Tribolium castaneum (Herbst). J. Stored Prod. Res. 1999, 35, 317-328.

29. Sakuma, M. Probit analysis of preference data. Appl. Entomol. Zool. 1998, 33, 339-347.

30. Liu, Z.L.; Liu, Q.R.; Chu, S.S.; Jiang, G.H. Insecticidal activity and chemical composition of the essential oils of Artemisia lavandulaefolia and Artemisia sieversiana from China. Chem. Biodiv. 2010, 7, 2040-2045.

31. Li, W.Q.; Jiang, C.H.; Chu, S.S.; Zuo, M.X.; Liu, Z.L. Chemical composition and toxicity against Sitophilus zeamais and Tribolium castaneum of the essential oil of Murraya exotica aerial parts. Molecules 2010, 15, 5831-5839.

32. Chu, S.S.; Liu, Q.R.; Liu, Z.L. Insecticidal activity and chemical composition of the essential oil of Artemisia vestita from China against Sitophilus zeamais. Biochem. Syst. Ecol. 2010, 38, 489-492.

33. Chu, S.S.; Liu, S.L.; Jiang, G.H.; Liu, Z.L. Composition and toxicity of essential oil of Illicium simonsii Maxim (Illiciaceae) fruit against the maize weevils. Rec. Nat. Prod. 2010, 4, 205-210.

34. Liu, Z.L.; Chu, S.S.; Jiang, G.H. Insecticidal activity and composition of essential oil of Ostericum sieboldii (Apiaceae) against Sitophilus zeamais and Tribolium castaneum. Rec. Nat. Prod. 2011, 5, 74-81.

35. Adams, R.P. Identification of essential oil components by gas chromatography/quadrupole mass spectroscopy; Allured: Carol Stream, IL, USA, 2001.

36. Carr, G.; Dean, C.; Whittaker, D. Terpenoid ether formation in superacids. J. Chem. Soc. Perkin Trans. 2 1988, 3, 351-354

37. Asakawa, Y.; Matsuda, R.; Tori, M.; Hashimoto, T. Preparation of biologically active substances and animal and microbial metabolites from menthols, cineoles and kauranes. Phytochemistry 1988, 27, 3861-3869.

38. Fox, D.J.; Pedersen, D.S.; Warren, S. Diphenylphosphinoyl-mediated synthesis of ketones. Org. Biomol. Chem. 2006, 4, 3102-3107.

39. Black, P.J.; Edwards, M.G.; Williams, J.M.J. Borrowing hydrogen: Indirect "Wittig" olefination for the formation of C-C bonds from alcohols. Eur. J. Org. Chem. 2006, 19, 4367-4378.

40. Suarez, L.E.C.; Menichini, F.; Monache, F.D. Tetranortriterpenoids and dihydrocinnamic acid derivatives from Hortia colombiana. J. Braz. Chem. Soc. 2002, 13, 339-344.

Sample Availability: Samples of the crude extracts and pure compounds are available from the authors.

(C) 2011 by the authors; licensee MDPI, Basel, Switzerland. This article is an open access article distributed under the terms and conditions of the Creative Commons Attribution license (http://creativecommons.org/licenses/by/3.0/). 